\title{
Attitudes of Non-Asthmatic Children Towards Their Asthmatic Peers Influence of interactions with asthmatic relatives and peers
}

*Mohammad Al-Motlaq ${ }^{1}$ and Nihaya Al-Sheyab²

$$
\begin{aligned}
& \text { مواقف الأطفال الغير مصابين بالربو بحاه أقراهم المصابين بالمرض المارض } \\
& \text { تأثير التفاعل مع بالربو الأقارب والأقران }
\end{aligned}
$$

محمد المطلق و نهايه الشياب

ABSTRACT: Objectives: This study aimed to examine non-asthmatic children's acceptance of and attitudes towards their asthmatic peers in Jordan. Methods: This descriptive cross-sectional study was conducted between September 2015 and January 2016 among 1,812 non-asthmatic children aged 9-13 years old at 10 schools in Zarqa, Jordan. Arabic versions of the Peers Attitude Towards Children with Asthma scale and the Asthma Knowledge Test for Children were used to assess attitudes towards children with asthma and asthma-related knowledge, respectively. Results: A total of 1,586 children participated in the study (response rate: 87.5\%). Of these, $158(10 \%)$ and $399(25.2 \%)$ children reported a family history of asthma or knew at least one person with asthma, respectively. Although 50.3\% stated that they would sit next to such children in the classroom, only $34.9 \%$ reported that they would be friends with an asthmatic child. However, $73.1 \%$ of the non-asthmatic children believed that asthmatic children were not pretending to be ill and $61.4 \%$ believed that such children were not ill due to their own carelessness. Female non-asthmatic children $(P<0.001)$, those with a family history of asthma $(P=0.004)$ and those who knew other individuals with asthma $(P<0.001)$ had significantly more positive attitudes towards and acceptance of their asthmatic peers. In addition, age was significantly related to attitude scores $(P<0.001)$. However, there was no correlation between asthma-related knowledge and the children's attitudes towards peers with asthma $(P=0.611)$. Conclusion: Previous interactions with asthmatic family members or peers were found to significantly influence non-asthmatic children's attitudes towards their asthmatic peers.

Keywords: Asthma; Children; Attitudes; Knowledge; Jordan.

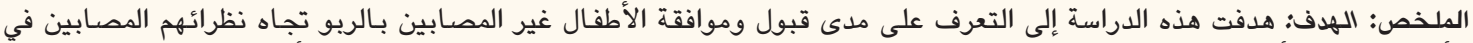

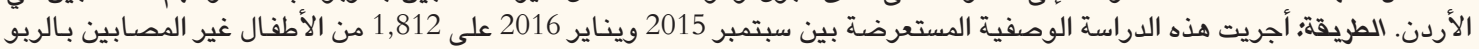

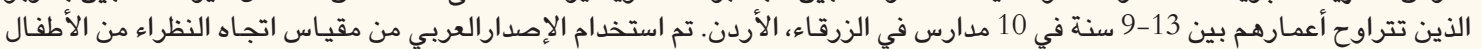

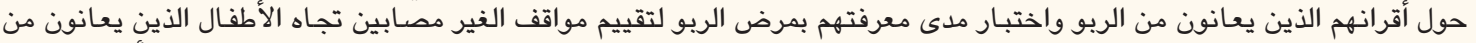

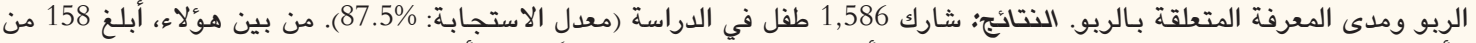

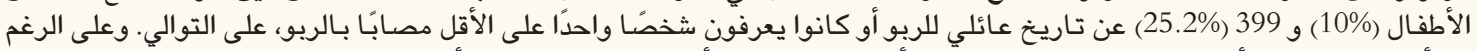

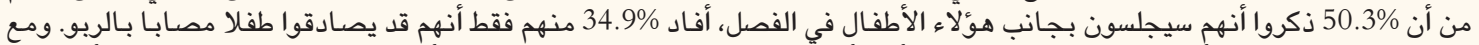

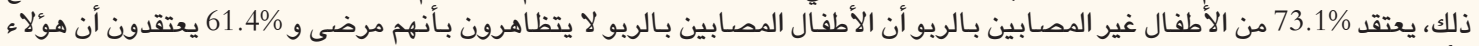

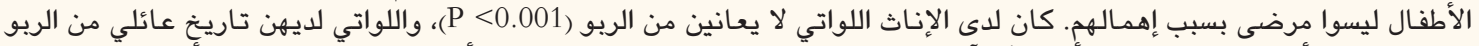

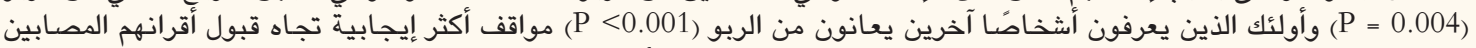

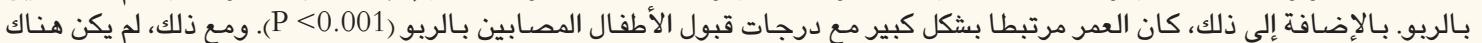

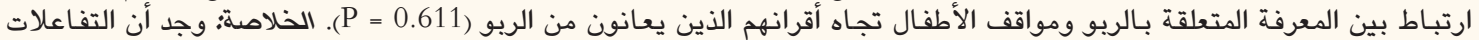

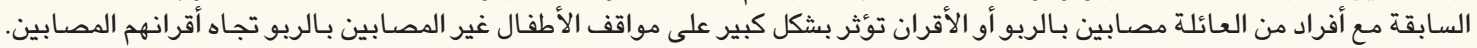

$$
\text { الكلمات المفتاحية: الربو؛ الأطفال؛ الاتجاهـات؛ المعرفه؛ الأردن. }
$$

\section{Advances in KNOWLEDGe}

In the current study, female non-asthmatic children, those with a family history of asthma and those who knew someone with asthma had significantly more positive attitudes towards their asthmatic peers in Zarqa, Jordan.

\section{Application to Patient Care}

Healthcare providers in Jordan should promote positive attitudes towards children with asthma in clinical practice.

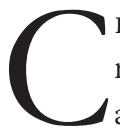

HILDHOOD ASTHMA IS A LONG-TERM RESPIratory disease which impacts both physical and emotional wellbeing, often affecting the patient's daily quality of life (QOL) ${ }^{1,2}$ Previous studies have indicated that children with chronic illnesses often suffer from reduced academic performance 
due to disease-associated exacerbations, absenteeism and stress. ${ }^{3,4}$ Moreover, children with illnesses are often less accepted or engaged with by their peers..$^{5-8}$ For children with asthma, QOL may be affected by social acceptance or rejection by their peers in light of the stigma associated with the disease..$^{3,9}$ In general, Graetz et al. found that children with asthma who were more frequently hospitalised were less preferred as playmates by other children and perceived to be more sensitive and isolated. ${ }^{5}$ Another study demonstrated that symptomatic evidence of a disease negatively influenced some children's perceptions of and responses towards their sick peers. ${ }^{10}$

Unfortunately, social rejection and negative attitudes often have an unfavourable impact on the wellbeing of the ill child., ${ }^{6,11-13}$ The role of peer support in facilitating psychosocial adjustment among children has proven beneficial in improving resilience and wellbeing. ${ }^{8}$ Therefore, direct contact between healthy and ill children is highly advised in order to effectively improve the attitudes of the former towards the latter. $^{7,11,14,15}$ Previous research has indicated that greater asthma-related knowledge and being female positively affect children's attitudes towards their asthmatic peers. ${ }^{11,16}$ Such research is important in order to identify appropriate interventions to improve asthma-related attitudes in schools and the wider community. Specifically, it is important to study whether having a family history of asthma or knowing others (i.e. a friend, peer or relative) with asthma positively contributes to children's acceptance of or attitudes towards their diseased peers.

In Jordan, the prevalence of asthma is comparable to that of other developed countries. ${ }^{17}$ However, this may be due to underdiagnosis of the condition; a review from the Middle East indicated a noticeable increase in the prevalence and burden of asthma due to increased public and professional awareness of the disease. ${ }^{18}$ Frequent asthma-related triggering factors include respiratory tract infections, exercise, dust and parental smoking. ${ }^{17,19}$ Nevertheless, there are few asthma health education and promotion programmes targeting children and adolescents in Jordan. ${ }^{19}$

This study aimed primarily to examine the association between attitudes towards peers with asthma among non-asthmatic children and having a family history of asthma or knowing someone with asthma. Based on the outcomes of studies evaluating perceptions of physical disability, it was hypothesised that interactions with family members or peers with asthma would positively influence acceptance of and attitudes towards asthmatic peers among nonasthmatic children. ${ }^{14,15}$ The second aim of the study was to investigate the relationship between non-asthmatic children's levels of asthma-related knowledge and their attitudes towards their asthmatic peers. Finally, the third aim was to determine asthma-related knowledge and attitudes among children without asthma.

\section{Methods}

This descriptive cross-sectional study was conducted between September 2015 and January 2016 at 10 schools in the second educational district of Zarqa, Jordan. These schools included nine governmental schools and one private school and were recruited from a list of 100 schools in Zarqa, including 29 male-only schools, 23 female-only schools and 48 coeducational schools. A simple random sampling technique was subsequently used to select one class of children from each grade between grades 4-7 at the selected schools. Overall, 1,812 non-asthmatic children aged 9-13 years old were invited to participate in the study.

Three questionnaire tools were utilised to gather data from the participants. Demographic information was elicited using a four-item questionnaire, including age, gender, the presence of a family history of asthma and pre-existing relations with individuals with asthma. Subsequently, the 10-item Peers Attitude Towards Children with Asthma (PACA) scale was used to measure attitudes towards (items 3, 4, 5, 7, 8 and 10) and acceptance of (items 1, 2, 6 and 9) children with asthma on two subscales. ${ }^{11}$ The children responded to each item with yes/no responses, with a score of one given to a positive response and zero to a negative response. After reverse scoring negatively-worded items, the scores were summed up to provide a total overall score, in which higher overall scores indicated more positive attitudes towards children with asthma. Finally, the 22-item Asthma Knowledge Test for Children was used to assess the children's general knowledge about asthma, including its triggers, symptoms, treatment and management. ${ }^{20}$ This questionnaire consisted of 21 true/false items and one item asking the child to list three symptoms of asthma. One point was awarded for each correct answer or symptom listed, for a maximum of 24 points. Correct responses to each item were summed to provide a total score.

All of the questionnaires were translated into Arabic and pilot-tested for comprehension and clarity among a group of children with similar characteristics to that of the study sample. The final questionnaires were distributed among selected classes with the aid of classroom teachers. When necessary, the teachers also helped the children to read and complete the forms. A total of 81 students who self-reported an asthma diagnosis were excluded from the analysis. 
Data were analysed using the Statistical Package for the Social Sciences (SPSS), Version 22.0 (IBM Corp., Armonk, New York, USA). Descriptive statistics were used to illustrate the characteristics and attitude scores of the sample. In addition, a correlation coefficient test was used to examine the relationship between asthma-related knowledge and attitude scores. A $P$ value of $\leq 0.050$ was considered statistically significant. In order to identify the effect of a family history of asthma and previous relations with other asthmatic individuals on the children's attitudes, a multiple regression analysis was performed using all factors associated with attitude scores as independent variables. However, this technique was not successful due to the violation of multiple regression assumptions (i.e. multicollinearity). Instead, a Student's t-test and analysis of variance were performed, with a Bonferroni adjustment made to the alpha value $(P<0.001)$.

Ethical approval to conduct this study was obtained from the Hashemite University Institutional Review Board (\#2015/2014/2/3) and the Ministry of Education in Jordan (\#2/7/1/8221). In addition, the appropriate authorities at each school gave permission for the study to be conducted. Parental informed consent was obtained for each of the children prior to their participation in the study.

\section{Results}

A total of 1,586 non-asthmatic children participated in the study (response rate: 87.5\%). Of these, 659 (41.6\%) were male and 927 (58.4\%) were female. A family history of asthma was reported by 158 children (10\%), while 399 (25.2\%) stated that they knew at least one person with asthma. The mean total PACA score was $4.97 \pm 2.11$ out of 10 , with mean total scores for the acceptance and attitudes subscales being $1.73 \pm 1.10$ out of 4 and $3.24 \pm 1.47$ out of 6 , respectively. Total knowledge scores ranged from $0-21$, with a mean score of $11.5 \pm 3.09$ out of 24 .

In terms of attitudes towards and acceptance of asthmatic children, the percentage of positive responses ranged from $30.1-59.9 \%$ for positivelyworded items and $26.9-56.9 \%$ for negatively-worded items. While $73.1 \%$ of students in the current study believed that children with asthma do not pretend to be sick and $61.4 \%$ believed that asthmatic children were ill due to factors other than carelessness, only $34.9 \%$ reported that they would be happy to accept children with asthma as their friends. In addition, only 30.1\% believed that such children could participate in sports, while just over half $(50.3 \%)$ did not mind sitting next to them. However, despite these generally negative attitudes, most children (59.9\%) stated that they did
Table 1: Attitudes towards children with asthma* among non-asthmatic children in Jordan $(\mathrm{N}=1,586)$

$\begin{array}{lc}\text { Item } & \begin{array}{c}\text { Positive } \\ \text { responses, } \\ \text { n (\%) }\end{array} \\ \text { Positively-worded items }\end{array}$

*Assessed using an Arabic version of the 10-item Peers Attitude Towards Children with Asthma scale..$^{1+}$ Percentages are not calcul-ated out of the total sample due to missing data for certain items.

not mind if their asthmatic peers used their inhalers in class [Table 1]. With regards to asthma-related knowledge levels, the percentage of correct responses to each item ranged widely from $15.2-79.4 \%$ [Table 2]. Overall, $74.1 \%$ of the children gave correct responses to six items, while $49.3 \%$ provided correct responses to 15 items.

Overall, female students $\left(\mathrm{t}_{[1,566]}=-4.3 ; P<0.001\right)$, those with a family history of asthma $\left(\mathrm{t}_{[1,566]}=2.9\right.$; $P<0.004)$ and those with prior knowledge of someone with asthma $\left(\mathrm{t}_{[1,566]}=-7.6 ; P<0.001\right)$ had significantly more positive attitudes towards their asthmatic peers [Table 3]. Age was also significantly positively correlated to attitude scores $(r=0.14 ; P<0.001)$. However, there was no correlation between levels of asthma knowledge and attitudes towards asthmatic peers $(\mathrm{r}=0.01 ; P=0.611)$.

\section{Discussion}

The current study aimed to explore the possibility that interactions with asthmatic family members or peers would have a positive influence on the acceptance of and attitudes of non-asthmatic children towards their 
Table 2: Asthma-related knowledge* among non-asthmatic children in Jordan $(\mathrm{N}=1,586)$

\begin{tabular}{|c|c|}
\hline Item & $\begin{array}{c}\text { Correct } \\
\text { responses, } \\
\mathbf{n}(\%)^{\dagger}\end{array}$ \\
\hline 1. Lots of children have asthma & $770(48.6)$ \\
\hline $\begin{array}{l}\text { 2. Children with asthma can play with other } \\
\text { children }\end{array}$ & $619(39.1)$ \\
\hline $\begin{array}{l}\text { 3. People with asthma can drink milk and eat } \\
\text { yoghurt }\end{array}$ & $1,214(76.6)$ \\
\hline $\begin{array}{l}\text { 4. Having the flu (influenza) can cause an } \\
\text { asthma attack }\end{array}$ & $930(58.7)$ \\
\hline 5. Smoking is acceptable for people with asthma & $241(15.2)$ \\
\hline $\begin{array}{l}\text { 6. People with asthma become addicted to their } \\
\text { medication }\end{array}$ & $967(61)$ \\
\hline $\begin{array}{l}\text { 7. If you do not have asthma now, you will never } \\
\text { get it }\end{array}$ & $582(36.7)$ \\
\hline $\begin{array}{l}\text { 8. An asthma attack is caused by hypersensitiv- } \\
\text { ity and inflammation in the airways of the lungs }\end{array}$ & $1,216(76.7)$ \\
\hline $\begin{array}{l}\text { 9. Most children with asthma are smaller than } \\
\text { other children }\end{array}$ & $561(35.4)$ \\
\hline 10. Asthma can be spread from person to person & $693(43.7)$ \\
\hline $\begin{array}{l}\text { 11. If one child in a family has asthma, then their } \\
\text { brothers and sisters will have asthma too }\end{array}$ & $391(24.7)$ \\
\hline $\begin{array}{l}\text { 12. People with asthma can die if they are not } \\
\text { treated }\end{array}$ & $1,237(78)$ \\
\hline $\begin{array}{l}\text { 13. Medicines that keep asthma from happening } \\
\text { should be taken every day }\end{array}$ & $1,175(74.1)$ \\
\hline $\begin{array}{l}\text { 14. A puffer (inhaler) should be used when a } \\
\text { person has an asthma attack }\end{array}$ & $965(60.9)$ \\
\hline $\begin{array}{l}\text { 15. Having pet birds is acceptable for people with } \\
\text { asthma }\end{array}$ & $320(20.2)$ \\
\hline $\begin{array}{l}\text { 16. Asthma attacks happen more frequently at } \\
\text { night }\end{array}$ & $1,057(66.7)$ \\
\hline $\begin{array}{l}\text { 17. It is acceptable for people with asthma to swim } \\
\text { and play sports }\end{array}$ & $532(33.6)$ \\
\hline 18. Asthma medicines can hurt the heart & $697(44)$ \\
\hline 19. Rest is needed to stop an asthma attack & $1,187(74.9)$ \\
\hline $\begin{array}{l}\text { 20. When asthma is controlled, all medicines can } \\
\text { be stopped }\end{array}$ & $781(49.3)$ \\
\hline $\begin{array}{l}\text { 21. With the right treatment, a child with asthma } \\
\text { can live a normal life }\end{array}$ & $1,259(79.4)$ \\
\hline \multicolumn{2}{|l|}{ 22. Can you list three signs of asthma? } \\
\hline No correct symptoms & $248(16.6)$ \\
\hline One correct symptom & $441(28.3)$ \\
\hline Two correct symptoms & $487(31.2)$ \\
\hline Three correct symptoms & $363(23.9)$ \\
\hline
\end{tabular}

"Assessed using an Arabic version of the 22-item Asthma Knowledge Test for Children..$^{20}$ Percentages are not calculated out of the total sample due to missing data for certain items.
Table 3: Factors influencing attitudes towards children with asthma* among non-asthmatic children in Jordan $(\mathrm{N}=1,568)^{\dagger}$

$\begin{array}{lccc}\text { Factor } & \text { n } & \begin{array}{c}\text { Mean attitude } \\ \text { score }\end{array} & \boldsymbol{P}_{\text {value }}{ }^{\ddagger} \\ \text { Gender } & & 4.7 \pm 1.9 & \\ \text { Male } & 644 & 5.2 \pm 2.2 & <0.001 \\ \text { Female } & 924 & & \\ \text { Family history of asthma } & & \\ \text { Present } & 149 & 5.5 \pm 2.2 & 0.004 \\ \text { Absent } & 1,419 & 4.9 \pm 2.1 & \end{array}$

Prior knowledge of someone with asthma

$\begin{array}{lrrr}\text { Present } & 399 & 5.7 \pm 2.1 & <0.001 \\ \text { Absent } & 1,169 & 4.7 \pm 2.0 & \end{array}$

$d f=$ degrees of freedom

*Assessed using an Arabic version of the 22-item Asthma Knowledge Test for Children..$^{20}$ The total number of children who completed both the knowledge and attitude questionnaires. ${ }^{7} A P$ value of $\leq 0.001$ was considered significant after a Bonferroni adjustment was made to the alpha value.

asthmatic peers. However, compared to other studies from developed countries which revealed more positive attitudes and higher levels of asthma-related awareness, the current study revealed that nonasthmatic Jordanian children held mostly negative attitudes towards their asthmatic peers and had low levels of asthma-related knowledge. ${ }^{11-13,21,22}$

In the present study, the majority of asthma knowledge-related items were answered incorrectly by most non-asthmatic children. This lack of knowledge extended across all aspects of the disease, including its causes, symptoms, treatment and management. A previous study conducted in northern Jordan similarly reported low levels of asthma-related knowledge among adolescents in contrast to studies from the USA. ${ }^{19,23,24}$ Additionally, the findings of the current study indicated a negative attitude trend extending across all components of the scale. Moreover, high knowledge scores did not necessarily correlate with more positive attitudes. This is in contrast to a previous study of Australian children which found that higher knowledge scores correlated positively with attitude scores. ${ }^{11}$ This variation in findings may be attributable to differences in the average knowledge scores between the two samples, particularly as the Australian children had higher total scores than children in the current sample. ${ }^{11}$ This finding suggests that attitudes should be measured while controlling for knowledge scores, particularly when assessing potential influences such as a family history of asthma or knowing others with asthma. 
A previous study found that a family history of asthma and prior knowledge of others with asthma were not significantly related to attitudes towards asthmatic peers among non-asthmatic Australian children. ${ }^{11}$ This finding was attributed to the high level of acceptance of asthmatic peers among their studied sample. In contrast, both of these factors along with being female were found to positively contribute to total attitude scores in the current study. The low level of acceptance of asthmatic peers noted in the present study underlines the importance of social interactions between non-asthmatic and asthmatic children so as to foster positive attitudes and acceptance among the former group towards the latter. ${ }^{12}$ Children with asthma have reported feelings of anxiety and embarrassment about their illness which affected their attitudes towards self-treatment. ${ }^{25}$ It is therefore important to change social perceptions of chronic illnesses in order to foster a positive attitude towards affected patients. ${ }^{6,10,16}$ Healthcare providers in Jordan should therefore seek to educate children regarding childhood asthma as well as promote positive attitudes towards asthmatic children among their non-asthmatic peers.

The current study was limited by its crosssectional nature which does not imply a causal relationship; an interventional case-control study might have produced more valid results. In addition, a longitudinal rather than descriptive design would have contributed to the strength of the findings. However, this could not be achieved due to feasibility-related constraints such as lack of time and funds. Another limitation of the study was the reliance on selfreported data potentially subject to reporting bias. In addition, this study was conducted in only one region of Jordan; as such, the results cannot be generalised on a national level.

\section{Conclusion}

The results of this study indicated low levels of asthmarelated knowledge and generally negative attitudes towards asthmatic peers among non-asthmatic students in Zarqa, Jordan. Gender, age, a family history of asthma and prior knowledge of someone with asthma positively influenced attitudes towards asthmatic peers. Therefore, additional interactions between non-asthmatic and asthmatic children may be helpful in improving children's attitudes towards their asthmatic peers. Healthcare professionals should encourage positive interactions between nonasthmatic and asthmatic children in order to improve the knowledge and attitudes of non-asthmatic children towards their asthmatic peers.

\section{CONFLICT OF INTEREST}

The authors declare no conflicts of interest.

\section{FUNDING}

This study was funded with the aid of a grant from the Ministry of Higher Education \& Scientific Research Support Fund in Jordan (grant \#MPH/1/10/2013).

\section{References}

1. von Mutius E. The burden of childhood asthma. Arch Dis Child 2000; 82:II2-5. doi: 10.1136/adc.82.suppl_2.ii2.

2. Woolcock AJ, Bastiampillai SA, Marks GB, Keena VA. The burden of asthma in Australia. Med J Aust 2001; 175:141-5.

3. Annett RD, Bender BG, DuHamel TR, Lapidus J. Factors influencing parent reports on quality of life for children with asthma. J Asthma 2003; 40:577-87. doi: 10.1081/JAS-120019030.

4. Celano MP, Geller RJ. Learning, school performance, and children with asthma: How much at risk? J Learn Disabil 1993; 26:23-32. doi: 10.1177/002221949302600103.

5. Graetz B, Shute R. Assessment of peer relationships in children with asthma. J Pediatr Psychol 1995; 20:205-16. doi: 10.1093/ jpepsy/20.2.205

6. Link BG, Phelan JC. Conceptualizing stigma. Annu Rev Sociol 2001; 27:363-85. doi: 10.1146/annurev.soc.27.1.363.

7. Jorm AF, Wright A. Influences on young people's stigmatising attitudes towards peers with mental disorders: National survey of young Australians and their parents. Br J Psychiatry 2008; 192:144-9. doi: 10.1192/bjp.bp.107.039404.

8. Olsson CA, Boyce MF, Toumbourou JW, Sawyer SM. The role of peer support in facilitating psychosocial adjustment to chronic illness in adolescence. Clin Child Psychol Psychiatry 2005; 10:78-87. doi: 10.1177/1359104505048793.

9. Asano M, Sugiura T, Miura K, Torii S, Ishiguro A. Reliability and validity of the self-report quality of life questionnaire for Japanese school-aged children with asthma (JSCA-QOL v.3). Allergol Int 2006; 55:59-65. doi: 10.2332/allergolint.55.59.

10. Guite JW, Walker LS, Smith CA, Garber J. Children's perceptions of peers with somatic symptoms: The impact of gender, stress, and illness. J Pediatr Psychol 2000; 25:125-35. doi: 10.1093/jpepsy/25.3.125

11. Al-Motlaq MA, Sellick K. I don't mind: Children's attitude towards their peers with asthma in primary schools. Child Aust 2014; 39:125-30. doi: 10.1017/cha.2014.10.

12. Gibson PG, Henry RL, Vimpani GV, Halliday J. Asthma knowledge, attitudes, and quality of life in adolescents. Arch Dis Child 1995; 73:321-6. doi: 10.1136/adc.73.4.321.

13. Shaw SF, Marshak HH, Dyjack DT, Neish CM. Effects of a classroom-based asthma education curriculum on asthma knowledge, attitudes, self-efficacy, quality of life, and self-management behaviors among adolescents. Am J Health Educ 2005; 36:140-7. doi: 10.1080/19325037.2005.10608175

14. Longoria L, Marini I. Perceptions of children's attitudes towards peers with a severe physical disability. J Rehab 2006; 72:19-25.

15. Vignes C, Godeau E, Sentenac M, Coley N, Navarro F, Grandjean H, et al. Determinants of students' attitudes towards peers with disabilities. Dev Med Child Neurol 2009; 51:473-9. doi: 10.1111/j.1469-8749.2009.03283.x

16. Brook U, Kishon Y. Knowledge and attitude of healthy high school students toward bronchial asthma and asthmatic pupils. Chest 1993; 103:455-7. doi: 10.1378/chest.103.2.455 
17. Abu-Ekteish F, Otoom S, Shehabi I. Prevalence of asthma in Jordan: Comparison between Bedouins and urban schoolchildren using the International Study of Asthma and Allergies in Childhood phase III protocol. Allergy Asthma Proc 2009; 30:181-5. doi: 10.2500/aap.2009.30.3208

18. Al-Motlaq M. Prevalence and factors affecting childhood asthma in the Middle East: A literature review. Middle East J Nurs 2009; 3:11-16.

19. Al-sheyab N, Gallagher R, Crisp J, Shah S. Peer-led education for adolescents with asthma in Jordan: A cluster-randomized controlled trial. Pediatrics 2012; 129:e106-12. doi: 10.1542/peds. 2011-0346.

20. Al-Motlaq M, Sellick K. Development and validation of an asthma knowledge test for children 8-10 years of age. Child Care Health Dev 2011; 37:123-8. doi: 10.1111/j.13652214.2010.01133.x
21. Hayes SE, Huang KY, Evans D, Bruzzese JM. Minors' attitudes towards peers with asthma: A developmental study. J Asthma 2013; 50:90-6. doi: 10.3109/02770903.2012.743153.

22. Roberts CA, Geryk LL, Sage AJ, Sleath BL, Tate DF, Carpenter DM. Adolescent, caregiver, and friend preferences for integrating social support and communication features into an asthma self-management app. J Asthma 2016; 53:948-54. doi: 10.3109/ 02770903.2016 .1171339 .

23. Haver HL, Stieb E. Abstract A14/238: Improving children's knowledge of asthma triggers. Paediatr Respir Rev 2006; 7:S279. doi: $10.1016 / j . p r r v .2006 .04 .040$

24. Cohen R, Franco K, Motlow F, Reznik M, Ozuah PO. Perceptions and attitudes of adolescents with asthma. J Asthma 2003; 40:207-11. doi: 10.1081/JAS-120017992.

25. Bruzzese JM, Fisher PH, Lemp N, Warner CM. Asthma and social anxiety in adolescents. J Pediatr 2009; 155:398-403. doi: 10.1016/j.jpeds.2009.04.004 